\title{
ARM
}

CLIMATE RESEARCH FACILITY

\section{Micropulse Lidar (MPL) \\ HANDBOOK}

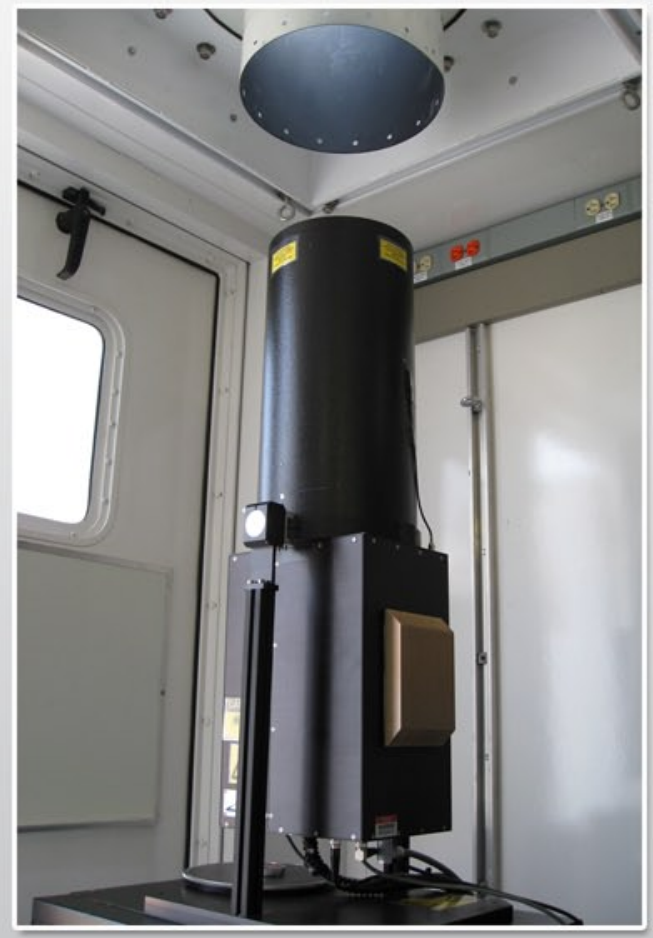

May 2012

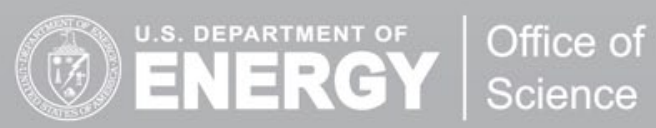




\section{DISCLAIMER}

This report was prepared as an account of work sponsored by the U.S. Government. Neither the United States nor any agency thereof, nor any of their employees, makes any warranty, express or implied, or assumes any legal liability or responsibility for the accuracy, completeness, or usefulness of any information, apparatus, product, or process disclosed, or represents that its use would not infringe privately owned rights. Reference herein to any specific commercial product, process, or service by trade name, trademark, manufacturer, or otherwise, does not necessarily constitute or imply its endorsement, recommendation, or favoring by the U.S. Government or any agency thereof. The views and opinions of authors expressed herein do not necessarily state or reflect those of the U.S. Government or any agency thereof. 


\section{Micropulse Lidar (MPL) Handbook}

R Coulter

May 2012

Work supported by the U.S. Department of Energy, Office of Science, Office of Biological and Environmental Research 


\section{Contents}

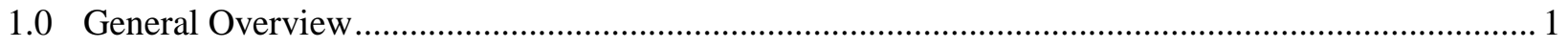

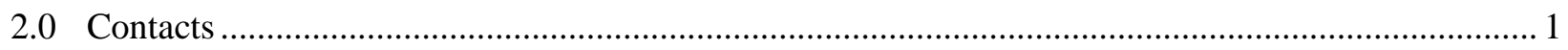

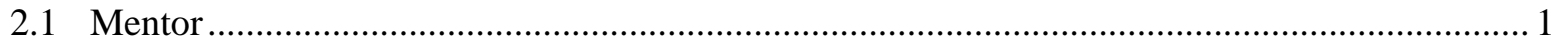

2.2 Instrument Developer .................................................................................................. 1

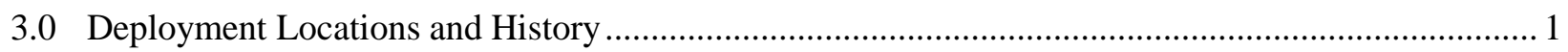

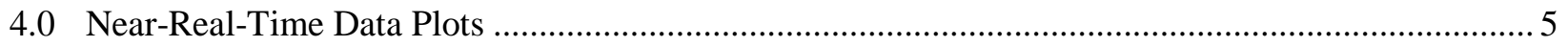

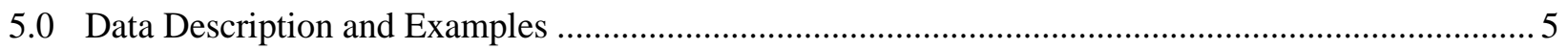

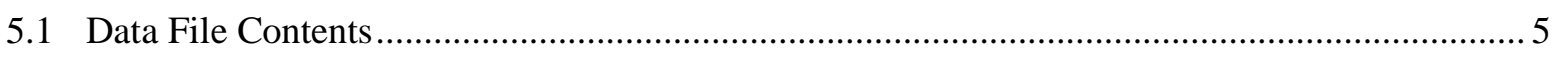

5.1.1 Primary Variables and Expected Uncertainty ................................................................ 5

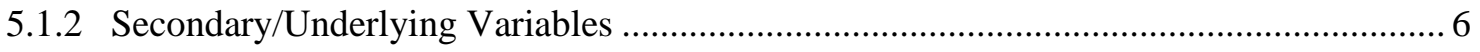

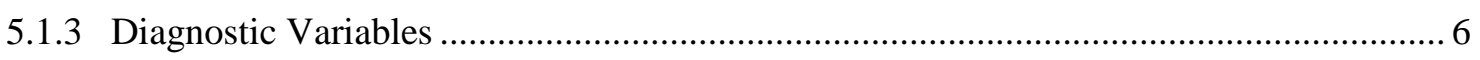

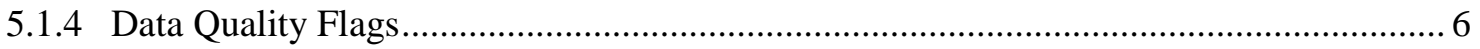

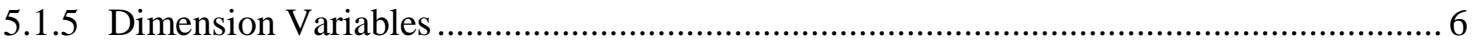

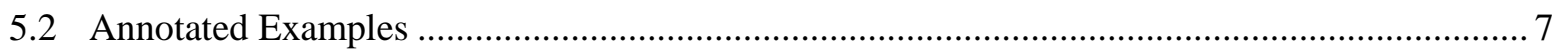

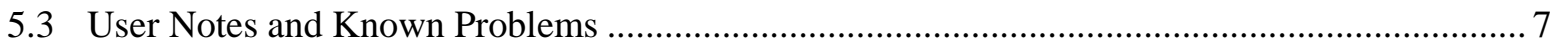

5.4 Frequently Asked Questions .......................................................................................... 7

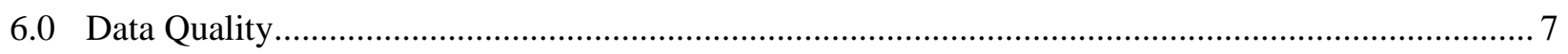

6.1 Data Quality Health and Status ................................................................................. 7

6.2 Data Reviews by Instrument Mentor.................................................................................... 7

6.3 Data Assessments by Site Scientist/Data Quality Office ....................................................... 8

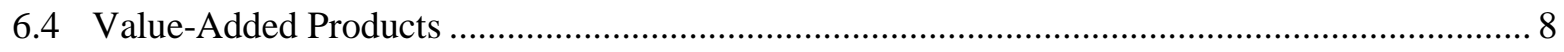

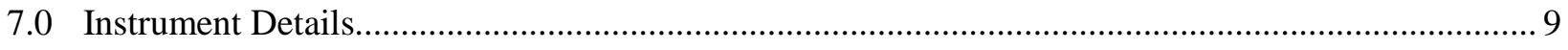

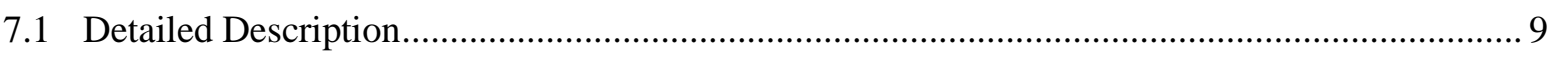

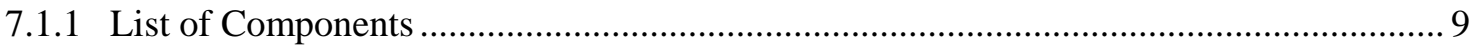

7.1.2 System Configuration and Measurement Methods ...................................................... 9

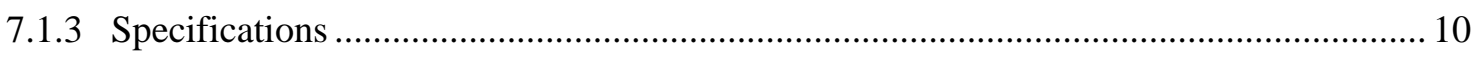

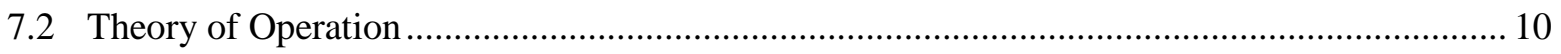

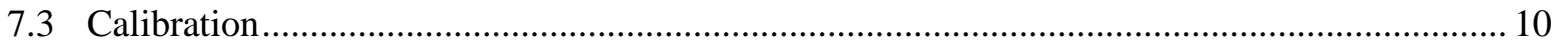

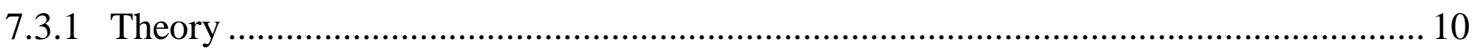

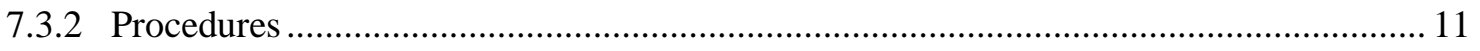

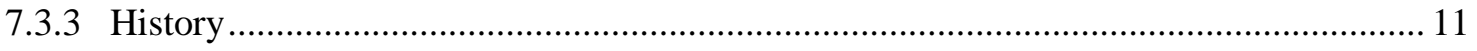

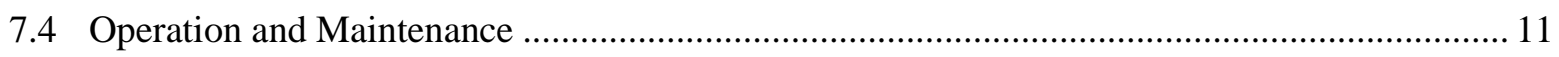

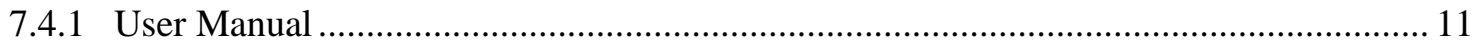

7.4.2 Routine and Corrective Maintenance Documentation ................................................... 11

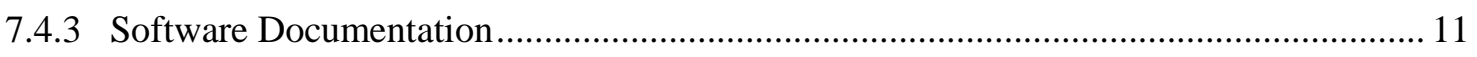

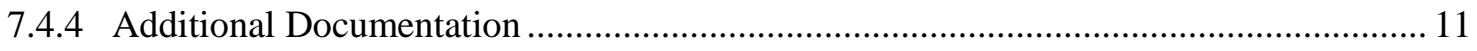




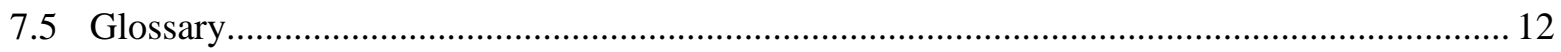

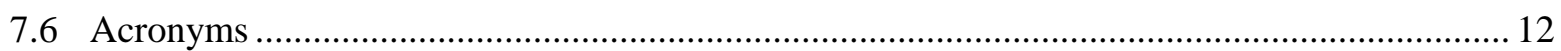

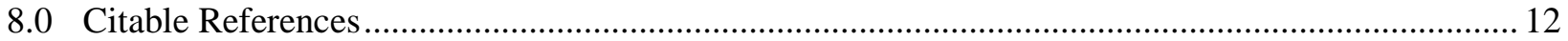




\section{Tables}

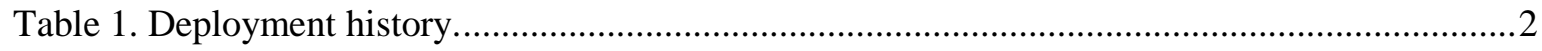




\subsection{General Overview}

The micropulse lidar (MPL) is a ground-based optical remote sensing system designed primarily to determine the altitude of clouds overhead. The physical principle is the same as for radar. Pulses of energy are transmitted into the atmosphere; the energy scattered back to the transceiver is collected and measured as a time-resolved signal. From the time delay between each outgoing transmitted pulse and the backscattered signal, the distance to the scatterer is infered. Besides real-time detection of clouds, postprocessing of the lidar return can also characterize the extent and properties of aerosol or other particleladen regions.

\subsection{Contacts}

\subsection{Mentor}

Richard Coulter

Argonne National Laboratory

Phone: (630) 252-5833

Fax: (630) 252-2959

rlcoulter@anl.gov

Timothy Martin

Argonne National Laboratory

Phone: (630) 252-8708

Fax: (630) 252-2959

\subsection{Instrument Developer}

Vendor/Manufacturer

Sigma Space Corporation

Savyasachee Mathur

Phone: (301) 552-6000

\subsection{Deployment Locations and History}

Prior to August, 2006, the MPLs were located at:

- Southern Great Plains Central Facility (SGP-C1)

- North Slope of Alaska, Barrow (NSA-C1)

- Tropical Western Pacific, Manus Island, Papua New Guinea (TWP-C1)

- Tropical Western Pacific, Nauru Island (TWP-C2)

- Tropical Western Pacific, Darwin, Australia (TWP-C3) 
These systems were non-polarized systems. In August 2006, new polarized (circular and linear crosspolarized) systems were put in place. These systems switched polarization states at 3-10 second intervals. Beginning in 2009, these systems were upgraded to switch on every pulse, that is, at a $2500-\mathrm{Hz}$ rate so as to eliminate aliasing affects.

The location and deployment history since 2006:

Table 1. Deployment history.

\begin{tabular}{|c|c|c|c|c|c|c|}
\hline Date & MPL & Site & Hours & Old S/N & New S/N & Comments \\
\hline $11 / 07 / 06$ & 102 & & Unknown & 52952 & 58017 & $\begin{array}{c}\text { SWAP 1.67A->1.0W (OLD } \\
\text { MPL) }\end{array}$ \\
\hline $5 / 03 / 07$ & 104 & Darwin & & & & $\begin{array}{c}\text { SWAP 0.85A->2.4uJ (low } \\
\text { output) }\end{array}$ \\
\hline $5 / 15 / 07$ & 104 & Darwin & & & & MPL removed for repair \\
\hline $5 / 15 / 07$ & 101 & Darwin & & & & MPL installed \\
\hline $10 / 10 / 07$ & 106 & SGP & & & & New detector installed \\
\hline $12 / 10 / 07$ & 409 & ANL & 3205 & & & Hour status \\
\hline $12 / 12 / 07$ & 104 & SGPTST & & & & MPL arrives from Sigma Space \\
\hline $12 / 19 / 07$ & 104 & SGPTST & & & & $\begin{array}{l}\text { MPL installed at SGP Central } \\
\text { Facility Guest Instrument trailer }\end{array}$ \\
\hline $2 / 15 / 08$ & 101 & Darwin & 9053 & & & Hour status \\
\hline $2 / 15 / 08$ & 104 & Spare & 8468 & & & Hour status \\
\hline $2 / 15 / 08$ & 105 & NSA & 2573 & & & Hour status \\
\hline $2 / 15 / 08$ & 106 & SGP & 4639 & & & Hour status \\
\hline $5 / 15 / 08$ & 107 & AMF & 8623 & & & Hour status \\
\hline $7 / 08 / 08$ & 409 & ANL & & & & MPL received from China \\
\hline $7 / 14 / 08$ & 409 & 5406 & & & & $\begin{array}{l}\text { MPL first tried at ANL after } \\
\text { China }\end{array}$ \\
\hline $9 / 03 / 08$ & 409 & ANL & & & & $\begin{array}{l}\text { MPL shipped to Sigma Space for } \\
\text { repair }\end{array}$ \\
\hline $9 / 24 / 08$ & 101 & Darwin & & & F6-68579 & $\begin{array}{c}\text { SWAP 1.5A->0.7W (low output) } \\
\text { Ryczek }\end{array}$ \\
\hline $9 / 29 / 08$ & 101 & Darwin & 4494 & & & Hour status \\
\hline 9/30/08 & 102 & Manus & 0051 & & & Hour status, no laser output \\
\hline $11 / 18 / 08$ & 101 & Darwin & & & & SWAP 1.55A->1.0W Ryczek \\
\hline $11 / 19 / 08$ & 104 & FSPOL & & & & MPL FSPOL upgrade to SGP CF \\
\hline $12 / 02 / 08$ & 104 & FSPOL & & & & MPL installed at SGP CF trailer \\
\hline $1 / 27 / 09$ & 106 & SGP & & & & New detector installed \\
\hline $2 / 04 / 09$ & 102 & Manus & & & & Swap, but faulty photonics \\
\hline $2 / 13 / 09$ & 108 & Nauru & & & & MPL removed to go to Darwin \\
\hline $2 / 26 / 09$ & 101 & Darwin & & & & $\begin{array}{l}\text { Removed for repair by Sigma } \\
\text { Space }\end{array}$ \\
\hline $2 / 26 / 09$ & 108 & Darwin & & & & MPL installed \\
\hline
\end{tabular}




\begin{tabular}{|c|c|c|c|c|c|c|}
\hline \multicolumn{7}{|c|}{ Table 1 (contd) } \\
\hline Date & MPL & Site & Hours & Old S/N & New S/N & Comments \\
\hline $2 / 26 / 09$ & 409 & $\overline{\mathrm{ANL}}$ & & & & $\begin{array}{l}\text { Received from Sigma Space } \\
\text { repaired }\end{array}$ \\
\hline $2 / 27 / 09$ & 104 & FSPOL & & & & $\begin{array}{c}\text { Shipped to Pagosa for RHUBC- } \\
\text { II }\end{array}$ \\
\hline $3 / 17 / 09$ & 105 & NSA & 52941 & & & Diode swap \\
\hline $3 / 31 / 09$ & 409 & ANL & & & & Connected at ANL for test, OK \\
\hline $4 / 01 / 09$ & 106 & SFP & 4498 & & & Hour status \\
\hline $4 / 09 / 09$ & 105 & NSA & 2620 & & & Hour status \\
\hline $4 / 09 / 09$ & 108 & Darwin & 0256 & & & Hour status \\
\hline $4 / 13 / 09$ & 105 & NSA & 22719 & & & $\begin{array}{c}\text { Diode reset hours to } 648 \text { (27 } \\
\text { days) }\end{array}$ \\
\hline $4 / 23 / 09$ & 107 & AMF & 14363 & & & MPL Azores install \\
\hline $4 / 30 / 09$ & 104 & FSPOL & 11202 & 52951 & F6-78499 & Pagosa install spare diode \\
\hline $4 / 30 / 09$ & 104 & FSPOL & 11202 & & & F6-78499 fiber broken \\
\hline $8 / 10 / 09$ & 104 & Chile & & & & Used laser diode installed \\
\hline $8 / 27 / 09$ & 104 & Chile & & & & New laser diode installed \\
\hline $8 / 31 / 09$ & 104 & Chile & & & & Try to align laser diode fiber \\
\hline $9 / 04 / 09$ & 107 & AMF & & & & New laser diode installed \\
\hline $10 / 12 / 09$ & 008 & Chile & & & & $\begin{array}{l}\text { Remove MPL104, install } \\
\text { MPL008 }\end{array}$ \\
\hline $10 / 24 / 09$ & 008 & Chile & & & & $\begin{array}{l}\text { End RHUBC II, MPL104, } \\
\text { MPL008 }\end{array}$ \\
\hline $12 / 01 / 09$ & 409 & ANL & & & & Deploy MPL409 AMF2 enc 484 \\
\hline $12 / 08 / 09$ & 107 & AMF & 2280.0 & & & $\begin{array}{l}\text { Update laser diode hour ctr from } \\
18607.9\end{array}$ \\
\hline $01 / 21 / 10$ & 104 & $\begin{array}{l}\text { ANL from } \\
\text { Chile }\end{array}$ & & & & Tested: weak/misaligned laser? \\
\hline $01 / 21 / 10$ & 008 & $\begin{array}{l}\text { ANL from } \\
\text { Chile }\end{array}$ & & & & Arrives at ANL from Chile \\
\hline $01 / 21 / 10$ & 4103 & ANL & 40 hours & & & MPL 4103 IDS first tested, OK \\
\hline $01 / 27 / 10$ & 104 & $\begin{array}{l}\text { ANL P.O. } \\
\text { 0A-47619 }\end{array}$ & & & & Ship to Sigma Space for repair \\
\hline $02 / 22 / 10$ & 101 & ANL & 57 hours & & & MPL 101 IDS first tested, OK \\
\hline 03/08/10 & 4103 & ANL & & & & $\begin{array}{c}\text { To Sigma Space for polarizer } \\
\text { repair }\end{array}$ \\
\hline $04 / 11 / 10$ & 102 & Manu & & & & Installed new FSPOL upgrade \\
\hline $04 / 15 / 10$ & 101 & ANL & & & & $\begin{array}{c}\text { Shipped to Sigma Space for } \\
\text { polarizer fepair, forward to New } \\
\text { York, Greenland }\end{array}$ \\
\hline $04 / 22 / 10$ & 4103 & ANL & & & & $\begin{array}{l}\text { Received from SS. Polarizer } \\
\text { repair? }\end{array}$ \\
\hline $05 / 04 / 10$ & 4103 & ANL & & & & $\begin{array}{c}\text { Deployed } 484 \text { in AMF2 } \\
\text { enclosure }\end{array}$ \\
\hline
\end{tabular}




\begin{tabular}{|c|c|c|c|c|c|c|}
\hline \multicolumn{7}{|c|}{ Table 1 (contd) } \\
\hline Date & MPL & Site & Hours & Old S/N & New $S / N$ & Comments \\
\hline $05 / 07 / 10$ & 4103 & ANL & 414 hours & & & \\
\hline $05 / 26 / 10$ & 101 & Greenland & 1389 & & & Installed \\
\hline 05/31/10 & 4103 & ANL & & & & $\begin{array}{l}\text { Shutdown at } 484 \text { ship to } \\
\text { RVCONN cruise }\end{array}$ \\
\hline $06 / 02 / 10$ & 106 & SGP & & & & Removed from service at SGP \\
\hline $06 / 02 / 10$ & 104 & SGP & 11640 & & & FSPOL installed at SGP \\
\hline $06 / 14 / 10$ & 4103 & RVCONN & & & & Deployed 06/14-18 \\
\hline $07 / 02 / 10$ & 4103 & ANL & & & & Deployed again at 484 \\
\hline $07 / 29 / 10$ & 4103 & ANL & & & & $\begin{array}{c}\text { Diode dying with only } 1673.1 \\
\text { hours }\end{array}$ \\
\hline 09/09/10 & 106 & NSA & & & & $\begin{array}{l}\text { Shipped from Sigma Spce, } \\
\text { FSPOL upgrade }\end{array}$ \\
\hline 09/13/10 & 4103 & MPL & & & & $\begin{array}{l}\text { Setup at Thunderhead V1 } \\
\text { STORMVEX }\end{array}$ \\
\hline $10 / 06 / 10$ & 4103 & & $\begin{array}{l}2368 \\
\text { hours }\end{array}$ & & & Laser diode dying \\
\hline $10 / 21 / 10$ & 4103 & & & & & $\begin{array}{c}\text { Sigma Space, liquid crystal } \\
\text { damaged }\end{array}$ \\
\hline $10 / 23 / 10$ & 008 & $\mathrm{AL}$ & & & & $\begin{array}{c}\text { Old MPL set up at ALTOS in } \\
\text { Alaska }\end{array}$ \\
\hline $11 / 02 / 10$ & 105 & & & & & $\begin{array}{c}\text { MPL } 105 \text { FSPOL arrives at } \\
\text { Manus }\end{array}$ \\
\hline $12 / 02 / 10$ & 101 & Greenland & 5111 & & & \\
\hline $02 / 02 / 11$ & 104 & SGP & & & & $\begin{array}{l}\text { Extreme water intrusion, ship to } \\
\text { Sigma Space }\end{array}$ \\
\hline $02 / 04 / 11$ & 107 & & & & & $\begin{array}{c}\text { From Azores to Sigma Space for } \\
\text { FSPOL }\end{array}$ \\
\hline $04 / 21 / 11$ & 101 & Greenland & 8453 & & & \\
\hline $04 / 21 / 11$ & 4012 & Steamboat & 6275 & & & \\
\hline $04 / 21 / 11$ & 106 & NSA & $\begin{array}{l}4986 \\
\text { hours }\end{array}$ & & & $\begin{array}{l}\text { ftdilog.txt: ReadData(): } \\
\text { 02780F00 01BE00A8 } 19242 \\
\text { return=19242 } 0\end{array}$ \\
\hline $04 / 21 / 11$ & 108 & Darwin & 38053 & & & \\
\hline $04 / 21 / 11$ & 105 & Manus & 15571 & & & $\begin{array}{c}\text { ftdilog.txt: ReadData(): } \\
\text { 024C0F00 019400A8 } 19242 \\
\text { return=19242 } 0\end{array}$ \\
\hline $04 / 25 / 11$ & 104 & SGP & 17540 & & & Returned from repair \\
\hline $04 / 26 / 11$ & 104 & SGP & & & & $\begin{array}{l}\text { Switch from SigmaMPL } 2.54 \text { to } \\
2.55\end{array}$ \\
\hline $04 / 29 / 11$ & 4103 & & & & & $\begin{array}{l}\text { Arrived at Sigma Space for } \\
\text { laser/polarizer repair }\end{array}$ \\
\hline $05 / 02 / 11$ & 106 & & & & & $\begin{array}{l}\text { Computer shipped from NSA to } \\
\text { SGP }\end{array}$ \\
\hline
\end{tabular}




\begin{tabular}{|c|c|c|c|c|c|c|}
\hline \multicolumn{7}{|c|}{ Table 1 (contd) } \\
\hline Date & MPL & Site & Hours & Old S/N & New S/N & Comments \\
\hline $06 / 08 / 11$ & 107 & & & & & $\begin{array}{l}\text { Shipped from Sigma Space to } \\
\text { SGP, FSPOL upgrade }\end{array}$ \\
\hline $06 / 10 / 11$ & 106 & & & & & $\begin{array}{l}\text { Returned to NSA, but not } \\
\text { running due to SW problems }\end{array}$ \\
\hline $06 / 15 / 11$ & 101 & Greenland & & & & New laser diode installed \\
\hline $06 / 16 / 11$ & 101 & Greenland & & & & $\begin{array}{l}\text { Laser diode hours changed from } \\
9235.4 \text { to } 36.0\end{array}$ \\
\hline $06 / 16 / 11$ & 102 & & & & & $\begin{array}{c}\text { At Sigma Space, repair } \\
\text { completed. Ship to Pagosa } \\
\text { Springs for India. }\end{array}$ \\
\hline $06 / 21 / 11$ & 106 & & & & & $\begin{array}{c}\text { Arrives at NSA. SigmaMPL not } \\
\text { installed. }\end{array}$ \\
\hline $06 / 27 / 11$ & 106 & & & & & $\begin{array}{l}\text { Working at NSA with } \\
\text { SigmaMPL } 4.06\end{array}$ \\
\hline $08 / 23 / 11$ & 107 & & & & & Installed at Manus \\
\hline $08 / 31 / 11$ & 108 & & & & & $\begin{array}{c}\text { Arrived at Sigma Space from } \\
\text { Darwin, FSPOL upgrade }\end{array}$ \\
\hline $09 / 29 / 11$ & 4103 & Gan & 6584 & & & Setup at AMF2 Maldives \\
\hline $10 / 13 / 11$ & 107 & Manus & 13064 & & & Running SigmaMPL2010R1.1 \\
\hline $10 / 13 / 11$ & 104 & SGP & 21625 & & & $\begin{array}{c}\text { Has been running SigmaMPL } \\
2.54\end{array}$ \\
\hline $10 / 27 / 11$ & 106 & NSA & & & & $\begin{array}{l}\text { SW upgrade from } 4.06 \text { to } \\
\text { 2010R1.1 }\end{array}$ \\
\hline
\end{tabular}

\subsection{Near-Real-Time Data Plots}

See http://plot.dmf.arm.gov/plotbrowser/.

\subsection{Data Description and Examples}

See MPL quick looks from NASA-Goddard Space Flight center.

\subsection{Data File Contents}

\subsubsection{Primary Variables and Expected Uncertainty}

The MPL has two measurement channels that record backscatter signals up to 20+ kilometers. The primary quantity derived from this signal is the lowest detected cloud base in meters, which is a VAP product. 
Additional quantities possible through post-processing of the raw signal return include a relative backscatter profile at $532 \mathrm{~nm}$. From the relative backscatter profile, other data products are possible, including multiple cloud decks, cloud and layer boundaries, cloud ice/water, as well as aerosol extinction and backscatter profiles.

\subsubsection{Definition of Uncertainty}

The uncertainties in reported cloud base height have several sources. There is an inherent calibration uncertainty of the timing electronics of about $2 \%$. This translates directly into an uncertainty of $+/-2 \%$ for all reported distances.

Also, the measured lidar profiles are collected in discrete "range bins" with finite width. Reported cloud heights are centered within the range bin, so cloud base heights will have an uncertainty of $+/-1 / 2$ the range resolution. Early MPL systems deployed at SGP and TWP C1 had a range resolution of 300 meters. ARM MPL systems are currently operated with 15-meter resolution.

There are also several uncertainties that are more difficult to quantify. The MPL is an eye-safe lidar, and as such, it transmits a very low power laser beam, typically less than $25 \mathrm{~mW}$ at $532 \mathrm{~nm}$. Thus, it is subject to signal-to-noise limitations in conjunction with solar background noise. Moreover, the laser beam is attenuated or extinguished as it passes through the atmosphere. These two effects combine to make detection of high thin clouds more difficult during the day. Furthermore, over time laser systems degrade and produce less powerful pulses, so the sensitivity of the MPL will depend on the health of the laser system in the MPL. In addition to these measurement limitations, there are other uncertainties that are difficult to quantify. Exactly "what is a cloud" is difficult to define. Algorithm differences can yield biases in reported cloud base height. More significantly, one algorithm may identify a particular atmospheric structure as being "cloud" while another algorithm may not, so algorithm sensitivity is also a difficult uncertainty to quantify.

\subsubsection{Secondary/Underlying Variables}

This section is not applicable to this instrument.

\subsubsection{Diagnostic Variables}

This section is not applicable to this instrument.

\subsubsection{Data Quality Flags}

Cloud base height is no longer reported by the MPL. This quantity is derived from post-processing as an ARM value-added product (VAP).

\subsubsection{Dimension Variables}

This section is not applicable to this instrument. 


\subsection{Annotated Examples}

This section is not applicable to this instrument.

\subsection{User Notes and Known Problems}

This section is not applicable to this instrument.

\subsection{Frequently Asked Questions}

What MPL datastream should I use for clouds?

Use ARSCL if it is available. If not, then use MPLnor. If neither, use the a1-level file.

What MPL datastream should I use for aerosol products?

ARM MPL aerosol retrievals are currently in development but are not operationally available. For limited periods, aerosol products from the ARM MPL at SGP are available from NASA's MPLnet. For qualitative indications of aerosol, the normalized backscatter profiles from MPLnor are excellent indicators of aerosol layers and relative abundance. Use of a1-level MPL datastreams for aerosol detection is not advised because significant corrections to the data are necessary, including overlap, deadtime, and afterpulse corrections.

What is the lowest cloud the MPL can detect?

The minimum detection height of the MPL is on the order of $150 \mathrm{~m}$. Below that the signal is swamped by after pulse.

\subsection{Data Quality}

\subsection{Data Quality Health and Status}

The Data Quality Office (DQO) website has links to several tools for inspecting and assessing MPL data quality:

- DQ Explorer

- DQ Plot Browser

- NCVweb: Interactive web-based tool for viewing ARM data

The tables and graphs shown contain the techniques used by ARM's data quality analysts, instrument mentors, and site scientists to monitor and diagnose data quality.

\subsection{Data Reviews by Instrument Mentor}

QC frequency: Monthly basis 
QC delay: Next week

QC type: Graphical plots

Inputs: Raw data

Outputs: Processed backscatter profiles

Reference: Routine data quality monitoring of the MPL at the SGP consists mainly of visual inspection of vertical time sections of backscattered signal.

\subsection{Data Assessments by Site Scientist/Data Quality Office}

All Data Quality and most Site Scientist techniques for checking have been incorporated within DQ Explorer.

\subsection{Value-Added Products}

Many of the scientific needs of the ARM Climate Research Facility are met through the analysis and processing of existing data products into value-added products (VAPs). Despite extensive instrumentation deployed at the ARM sites, there will always be quantities of interest that are either impractical or impossible to measure directly or routinely. Physical models using ARM instrument data as inputs are implemented as VAPs and can help fill some of the unmet measurement needs of the program.

Conversely, ARM produces some VAPs not in order to fill unmet measurement needs, but instead to improve the quality of existing measurements. In addition, when more than one measurement is available, ARM also produces "best-estimate" VAPs.

Two VAPs currently use the raw MPL datastream. Whenever possible, the following value-added products should be used in preference to the raw or a1-level MPL datastream.

- MPLnor: "MPLnor” stands for MPL normalized. It produces "normalized” backscatter profiles (in arbitrary units) with all known instrument artifacts removed. To improve signal to noise, MPLnor applies further temporal and spatial averaging. It also reports up to three layers of clouds along with cloud base and cloud top when possible. Both a "sensitive" and "robust" cloud mask are provided where the "robust" cloud mask is simply the "sensitive" mask with some filters applied to remove false positives.

- ARSCL: “ARSCL” stands for Active Remotely Sensed Cloud Locations. It represents a composite product combining measurements from ceilometers, lidar, and radar. Lidar and radar measurements are complementary in that lidar are more sensitive to smaller particles often found in cirrus or low water vapor clouds. However, radar is able to penetrate multiple cloud decks that are impossible for lidar to penetrate. Thus, this composite product provides the best of both instruments and is currently ARM's last word on cloud detection.

In addition, several other VAPs involving MPL measurements are under development including:

- Thin-cloud optical depth retrieval 
- Aerosol properties retrievals

- Depolarization ratios

- Slant-path optical depth retrievals.

\subsection{Instrument Details}

\subsection{Detailed Description}

\subsubsection{List of Components}

The MPL consists of four main components: (1) a computer, (2) a dedicated data acquisition and lidar control system, (3) a diode-pumped Nd-YLF laser system, and (4) a co-axial transceiver for transmitting the laser pulses and detecting the collected photons. Following is a description of each component:

1. The Computer: Currently, laptops are used with all ARM MPL systems. All laptops are using the CORE-PC operating system developed by ARM.

2. Lidar Control System: The lidar control system, custom produced by Sigma Space, provides conditioned power to the photon detector and laser energy monitor. It contains an integrated $\mathrm{A} / \mathrm{D}$ converter for reporting of vital system parameters to the instrument PC. It also contains the rangeselectable multi-channel scalar which accumulates the range-resolved backscatter profiles.

3. At present, all ARM MPL systems have incorporated the multi-channel scanner into the transceiver package. The laser power supply, made by Photonics, Inc. remains separate from the transceiver.

4. Laser-Diode Pumped Nd-YLF Laser System: The laser power supply provides CW laser diode infrared pump radiation to the Nd-YLF laser head within the transceiver. The power supply also controls the pulse repetition rate of the Nd-YLF laser head incorporated into the MPL transceiver (described below). Originally, all MPL systems used Spectra Physics lasers (model 7300 or "RSeries"), but as these lasers were discontinued, the lasers have been supplied by Photonics, Inc.

5. Co-Axial Transceiver: The "transceiver" serves as both transmitter of the outgoing laser pulses and receiver of backscattered light. Approximately 1.0 watt of infrared CW pump radiation is converted to about $25 \mathrm{~mW}$ pulses of green laser light ( $532 \mathrm{~nm}$ ) at $2500 \mathrm{~Hz}$ by the Nd-YLF laser head with nonlinear optical frequency doubler. The pulses of green light are passed through a linear polarizing beam splitter, a depolarizing wedge, and expanded to fill an 8" Celestron telescope.

The detection optics begins with the same 8" Celestron telescope. Returning photons incident on the telescope are collected and pass through the depolarizing wedge. About half of the collected photons pass through the polarizing beam splitter cube and half are reflected. Light passing through the beam splitter is collimated and passed through two narrow-band interference filters $(0.27 \mathrm{~nm}$ fwhm $)$ in order to reject most of the ambient light, and is ultimately focused onto a photon counting APD module.

\subsubsection{System Configuration and Measurement Methods}

The MPL is configured to operate autonomously in an unattended manner 24 hours a day. Standard ARM deployments have the MPL oriented vertically (or slightly off vertical). 


\subsubsection{Specifications}

Wavelength of laser pulse: $532 \mathrm{~nm}$

Length of laser pulse: $\sim 10 \mathrm{~ns}=3 \mathrm{~m}$

Range resolution (height interval): $15 \mathrm{~m}$

Maximum range for cloud base height: $18 \mathrm{~km}$

Typical averaging: $10 \mathrm{sec}$

\subsection{Theory of Operation}

The principle is straightforward. A short pulse of laser light is transmitted from the telescope. As the pulse travels along, part of it is scattered by molecules, water droplets, or other objects in the atmosphere. The greater the number of scatterers, the greater the part scattered. A small portion of the scattered light is scattered back, collected by the telescope, and detected.

The detected signal is stored in bins according to how long it has been since the pulse was transmitted, which is directly related to how far away the backscatter occurred.

The collection of bins for each pulse is called a profile. A cloud would be evident as an increase or spike in the back-scattered signal profile, since the water droplets that make up the cloud will produce a lot of backscatter.

\subsection{Calibration}

\subsubsection{Theory}

Little calibration is necessary for cloud-base height determination. To fix the distance scale, it is necessary to use a calibrated-pulse generator capable of producing a trigger pulse and a second delayed pulse with an accurately known time lag. The two pulses are used to mimic a transmitted laser pulse and detected backscatter pulse with time delay relating to a simulated distance.

Absolute calibration of the magnitude of the lidar signal is much more difficult. The following instrument-level corrections are required:

1. “Dead-time” correction to account for detector non-linear response

2. Detector "afterpulse” subtraction

3. Background subtraction

4. Range-squared correction

5. Near-field detector overlap correction

Energy-monitor normalization. 
Even after these various corrections are applied, the overall system transmittance is only coarsely known. Determination of this overall system calibration is typically obtained by comparison against other external measurements, modeled results, or both.

\subsubsection{Procedures}

This section is not applicable to this instrument.

\subsubsection{History}

Each of the calibrations described in the above section are applied by the MPLnor value-added product. The detector deadtime corrections are from vendor-supplied data sheets unique to each detector. Each of the other corrections is determined either through measurements conducted during installation, or from the real-time data.

See the table in section 3 for details on maintenance, repair, and system disposition.

\subsection{Operation and Maintenance}

\subsubsection{User Manual}

This section is not applicable to this instrument.

\subsubsection{Routine and Corrective Maintenance Documentation}

Little maintenance is required other than routine cleaning of the viewport window and gentle cleaning of dust from the telescope. Occasionally, the software or computer may lock up so visual confirmation that the program is operating, that the clock is updating, and that the displayed measurement agrees with reality are also required.

Both the co-pol and x-pol signals are displayed on the local MPL computer. The low-level signal should usually show a marked difference between the co (green) and x (red) polarized signal returns because there is little cross-polarized signal from aerosols or water droplets. For many clouds, the red and green colored traces will often become similar, indicating that the signal source is ice instead of water. If there is little difference between the two signal returns for all heights and several days, there may be a problem with the polarizer, and the mentor should be notified. The laser current should usually be between 0.5 and 1.0 amp, and the laser energy should be between 2 and $7 \mathrm{uJ}$.

\subsubsection{Software Documentation}

This section is not applicable to this instrument.

\subsubsection{Additional Documentation}

This section is not applicable to this instrument. 


\subsection{Glossary}

See the ARM Glossary.

\subsection{Acronyms}

lidar: light detection and ranging

Also see the ARM Acronyms and Abbreviations.

\subsection{Citable References}

Campbell, JR, DL Hlavka, EJ Welton, CJ Flynn, DD Turner, JD Spinhirne, and VS Scott. 2002. "Fulltime Eye-Safe Cloud and Aerosol Lidar Observation at Atmospheric Radiation Measurement Program Sites: Instruments and Data Processing.” Journal of Atmospheric and Oceanic Technology 19: 431-442.

Spinhirne, JD. 1993. “Micro pulse lidar.” IEEE Transactions on Geoscience and Remote Sensing 31: 48-55.

Spinhirne, JD, JAR Rall, and VS Scott. 1995. “Compact eye safe lidar systems.” Review of Laser Engineering 23: 112-118. 


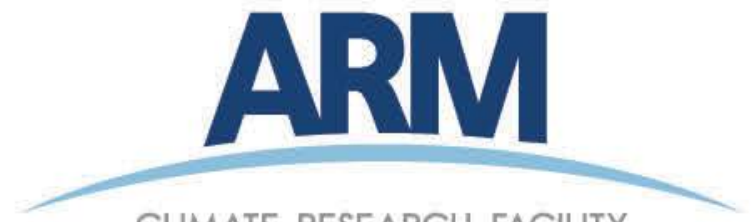

CLIMATE RESEARCH FACILITY

www.arm.gov

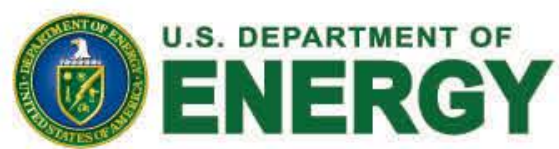

Office of Science 